\title{
Enfrentamento de desastres naturais: $O$ uso de um coping coletivo
}

\author{
Fernanda Menna Barreto Krum \\ Denise Ruschel Bandeira
}

Universidade Federal do Rio Grande do Sul, Porto Alegre-RS, Brasil

\begin{abstract}
Resumo: Os desastres naturais estão, atualmente, entre os mais comuns tipos de trauma. O impacto sofrido pelos indivíduos e pela comunidade atingida gera inúmeras respostas emocionais, tornando imperativa a mobilização de esforços para lidar com o evento. Esses são entendidos como estratégias de coping utilizadas para adaptar-se a situações estressoras. Muitos modelos e classificações foram propostos para explicar este conceito, entretanto a maioria permanece com uma percepção individual do processo. O modelo multi-axial de coping de Hobfoll traz uma perspectiva social ao fenômeno, vinculando o indivíduo ao contexto em que está inserido. Nesse sentido, sugere-se uma alternativa de entendimento do coping de vítimas de desastres naturais, propondo o conceito de coping coletivo.
\end{abstract}

Palavras-chave: Desastres naturais. Estilos de enfrentamento. Ambientes sociais.

\section{Dealing with natural disasters: The use of collective coping}

\begin{abstract}
Natural disasters are currently among the most common sources of trauma. Their impact on the community and its individuals cause a variety of emotional responses, which leads to an urgent need of mobilizing efforts to deal with such events. These efforts are understood as the coping strategies one uses to adapt to a stressful situation. Many models and classifications were proposed to explain this concept, but the majority remains with an individual perception of the process. The Hobfoll's multi-axial model of coping gives a social perspective for this phenomenon, linking the individual with his(er) context. Through this model, an alternative understanding of the coping process of victims of natural disasters is suggested: the concept of collective coping.
\end{abstract}

Keywords: Natural disasters. Coping styles. Social environments.

\section{Afrontamiento de desastres naturales: El uso de un coping colectivo}

Resumen: Actualmente, los desastres naturales son los más comunes entre los diferentes tipos de trauma. El impacto sufrido por las personas y por la comunidad afectada genera innumeras respuestas emocionales, haciendo imperativo movilizar recursos para hacer frente al evento. Esos son entendidos como estrategias de coping utilizadas para adaptarse a situaciones de estrés. Muchos modelos y clasificaciones fueron propuestos para explicar este concepto, sin embargo la mayoría permanece con una percepción individual del proceso. El modelo multiaxial de coping de Hobfoll trae una perspectiva social al fenómeno vinculando el individuo al contexto en el que está inserido. En este sentido, se sugiere una alternativa de entendimiento del coping de víctimas de desastres naturales, proponiendo el concepto de coping colectivo.

Palabras clave: Desastres naturales. Estilos de enfrentamiento. Ambiente social. 


\section{Introdução}

Considerando os desastres como eventos ambientais estressantes caracterizados em um nível mais amplo como eventos traumáticos, o estresse e as estratégias de coping ${ }^{1}$ para lidar com estes passam a ser conceitos importantes. A sistematização do estresse e do coping em termos conceituais vem sendo feita há algumas décadas, bem como este foi tomado como objeto de pesquisa no campo científico. Contudo, ainda não há um consenso acerca da definição dos termos que concilie todos os estudiosos (Lazarus \& Folkman, 1984).

Mais recentemente, observa-se um número crescente de estudos enfocando grupos e até mesmo comunidades inteiras atingidas por desastres. Paralelamente a isto, algumas perspectivas teóricas acerca do estresse e do coping têm desenvolvido uma visão mais social de como tais conceitos operam em termos de um processo coletivo. É nesta direção que o presente artigo propõe-se a discutir teoricamente uma alternativa de entendimento do coping de vítimas de desastres naturais, propondo o conceito de coping coletivo.

\section{Estresse e Teoria de Conservação de Recursos}

O estresse compreende inúmeros processos e variáveis. Sendo assim, o arcabouço teórico adotado para entender esse conceito deve conter diversos níveis de análise que especifiquem os antecedentes, os processos e os resultados relevantes. Lazarus e Folkman (1984) conceituam o estresse psicológico como uma relação particular entre o indivíduo e o contexto ambiental, avaliada pela pessoa como indo além do que pode suportar, isto é, sobrecarregando ou excedendo seus recursos pessoais e ameaçando seu bem-estar. Esse modelo, segundo Hobfoll (1989) considera a percepção do indivíduo como sendo o fator principal que define se a situação é ou não avaliada como estressante e é interpretado no meio científico como um tipo de modelo homeostático e de equilíbrio. Em outra perspectiva, modelos de transição são propostos, os quais sugerem que o desequilíbrio

\footnotetext{
${ }^{1}$ Não havendo na língua portuguesa uma palavra capaz de expressar a complexidade do conceito coping, optou-se pela não tradução do termo. Significados possíveis da palavra coping em português podem relacionar-se a "lidar com", "enfrentar" ou "adaptar-se a".
}

ocorre independentemente de a demanda real ou percebida ultrapassar a capacidade real ou percebida de enfrentá-lo. Esta idéia permite uma maior eqüidade na ênfase entre o ambiente e os fatores pessoais quando comparado ao modelo anterior, focado na percepção individual do evento estressante, e ainda se esforça no intuito de integrar as sobreposições dos achados fisiológicos, psicológicos e sociais do estresse. Entretanto, o problema da separação e definição do circuito demanda e capacidade de enfrentamento, mantém-se inalterado.

O entendimento de Hobfoll (1989) acerca do fenômeno do estresse considera não somente a percepção do indivíduo sobre a situação, visão cognitivista, nem exclusivamente o contexto em que este fato está inserido, entendimento ambientalista. Embora a origem do estresse, de acordo com Hobfoll (1998), seja biológica e relacionada com exigências biológicas, é da mesma forma significativamente moldada pela experiência cultural. Em seu ponto de vista o estresse está baseado em um modelo de desenvolvimento social e interdependente, o qual pressupõe os indivíduos nidificados em um contexto social e cultural - tanto o indivíduo quanto o contexto são vitais. Nesse sentido, as relações com as estruturas macrossociais são menos relevantes para o entendimento do estresse, contudo as estruturas sociais de nível intermediário, como as famílias e a vizinhança propriamente dita, são bastante representativas para tal proposta. São elas que proporcionam que o estresse seja analisado para além do indivíduo, mas não correndo o risco da perda deste nas estruturas macro sociais. As estruturas mesossociais, como denominou Hobfoll (1998), incluem os vínculos familiares, instituições religiosas, organizações trabalhistas e de caridade, vizinhança e grupos étnicos.

Esta sistematização das interações indivíduoambiente se aproxima fortemente do modelo bioecológico reformulado a partir da Teoria dos Sistemas Ecológicos do Desenvolvimento Humano proposto por Bronfenbrenner (1996). Este estuda o desenvolvimento humano através de quatro núcleos interrelacionados: o processo, a pessoa, o contexto e o tempo. O contexto diz respeito ao que Bronfenbrenner (1996) explicou como não se limitando a um ambiente imediato, mas como uma dimensão que é analisada através das interconexões 
de quatro níveis ambientais: o microssistema, o mesossistema, o exossistema e o macrossistema. Esta concepção foi proposta topologicamente como uma organização de encaixe de estruturas concêntricas, uma contida na outra, o chamado meio ambiente ecológico. Dessa forma, é através das interações que a pessoa estabelece, denominadas pelo autor como os processos proximais, nos diversos contextos com os quais mantém contatos diretos ou indiretos, que o estresse deve ser analisado e entendido.

Utilizando a linguagem de Hobfoll (1998), o estresse emerge, então, da dificuldade de realizar objetivos comuns que os membros de uma cultura possuem, começando pela porção do biológico e se estendendo até as relações e os rituais sociais complexos refletidos em uma sociedade. As pessoas são primeiramente impressas de suas características biológicas para mais tarde aprenderem a reconhecer que elementos do ambiente lhe são importantes. Muitos desses elementos estão relacionados com o conhecimento e o domínio do ambiente em que vivem, para que assim possam adquiri-los e protegê-los. A esses elementos que os indivíduos valorizam Hobfoll (1989, 1998) chamou de recursos, os quais são definidos por ele como:

Recursos incluem os objetos, condições, características pessoais e energias que são valorizadas para a sobrevivência, direta ou indiretamente, ou que servem como meio de atingir esse fim. Eu delimito a dimensão dos recursos como aqueles que são valorizados por uma ampla classe de indivíduos e que são percebidos extremamente salientes tanto para as pessoas em geral bem como para o sujeito. (Hobfoll, 1998, p.54).

Exemplos de recursos primários compreendem comida e abrigo, que se relacionam diretamente com a sobrevivência. Os recursos secundários incluem o senso de conhecimento e domínio de determinado fenômeno, assistência à saúde e transporte, os quais são ferramentas que aumentam a probabilidade de obter e proteger os recursos primários. Nesse contexto, as culturas avançaram e outras prioridades de vida foram substituindo a sobrevivência biológica. Mais distantes, mas também importantes são os recursos terciários como, por exemplo, o status social.
Este é apenas simbolicamente vinculado com a necessidade de sobrevivência como um valor que provê um senso de se estar distante da pobreza e consequentemente da falta de comida e abrigo (Hobfoll, 1998). É nesse sentido que Hobfoll (1989) explicita que existem dois níveis de valor dos recursos na vida das pessoas: um instrumental e o outro simbólico que auxilia o indivíduo a definir sua identidade.

É nessa perspectiva que a idéia central da Teoria de Conservação de Recursos proposta por Hobfoll $(1989,1998)$ concentra-se no fato de que as pessoas se esforçam para obter, conservar e proteger os elementos que valorizam. Somado a isto, ainda se esforçam por promover o que valorizam. Os recursos são, sozinhos, a unidade necessária para se entender o estresse, na qual pode se prever sua ocorrência como um resultado de circunstâncias que representam: ameaça da perda dos recursos ou perda verdadeira dos recursos requeridos para sustentar os indivíduos nidificados em famílias inseridas em uma organização social. Além disso, em razão das pessoas investirem no que acreditam que irão obter mais tarde, o estresse pode ocorrer em uma terceira situação: quando os indivíduos não recebem ganhos razoáveis por eles mesmos ou por seus grupos sociais seguidos de tal investimento, tornando-se isto, por si só, uma perda.

Tal teoria pressupõe quatro tipos de recursos. Os recursos de objeto incluem recursos que apresentam a presença física e que são valorizados por sua relação direta com a necessidade de sobrevivência ou pela sua vinculação com status e auto-estima. Eles compreendem o lar, o transporte e alguns objetos de fetiche. Os recursos de condições são importantes pelo fato de que eles, muitas vezes, propiciam o acesso a outros recursos. Condições são recursos quando se configuram em estruturas ou estados que permitem o acesso ou a posse de outros recursos. Eles obtêm valor em si próprio justamente pelo amplo papel de aquisição e proteção que exercem. Recursos de condições compreendem o sentir-se saudável, o estar empregado, o estar casado e, em algumas culturas ser o primeiro homem de uma prole, por exemplo. Características pessoais incluem tanto habilidades quanto traços individuais como possibilidades de recursos. Os primeiros são as habilidades ocupacionais, desenvoltura social e liderança. Os segundos dizem respeito ao nível de 
auto-estima, otimismo, auto-eficácia e esperança. Os recursos de energia não possuem um valor intrínseco, se não derivam o seu valor de sua capacidade em ser o meio de troca entre as outras três categorias de recursos. São eles dinheiro, crédito, tempo e conhecimento. Eles podem ser investidos ou retidos com o objetivo de aumentar a aquisição de recursos e a proteção contra a perda de recursos. Muitos elementos devem ser avaliados e entendidos como apresentando atributos de mais de um tipo de recurso, porém esta categorização oferece uma operacionalização e uma compreensão mais objetiva do processo de estresse (Hobfoll, 1998).

\section{Coping: uma nova perspectiva}

Esse processo instalado em função de uma ameaça ou perda real dos recursos promove os esforços realizados pelas pessoas em conservar, proteger ou reaver os elementos que valorizam. Estes esforços vão ao encontro do conceito de coping, considerando que estes dizem respeito ao modo como as pessoas lidam com dificuldades e situações estressantes. Tal referência é descrita na literatura pelo conceito de coping - conjunto de estratégias utilizadas pelos indivíduos para enfrentarem circunstâncias adversas e para a elas se adaptarem (Suls, David \& Harvey, 1996). Na busca por um melhor entendimento da estrutura e funcionamento do coping, surgiram modelos explicativos na perspectiva cognitivista e processual. Dentre elas, destaca-se o "Modelo de Processamento de Stress e Coping" de Lazarus e Folkman (1984), que compreende as seguintes idéias: (a) coping é um processo orientado e não uma característica, que ocorre na interação entre indivíduo e ambiente; (b) como processo, constitui-se na mobilização de esforços e não na automatização de comportamentos ou pensamentos, os quais não exigem empenho do sujeito; (c) como esforço na administração de situações estressantes, permite incluir tudo que a pessoa faz ou pensa independente de ser eficaz ou não, o que exclui a noção de resultado; e, (d) como administração de situações estressantes, não considera o controle ou domínio, mas sim a minimização, a evitação, a tolerância ou a aceitação do evento estressor. A partir disso, coping é definido como os constantes e mutáveis esforços cognitivos e comportamentais utilizados pelo indivíduo para lidar com demandas internas e/ou externas específicas, caracterizadas como estressores, ou seja, que sobrecarregam ou excedem seus recursos pessoais.

As características desta abordagem, para Lazarus e Folkman (1984), pressupõem observar e avaliar o que a pessoa realmente pensa ou faz e não o que ela costuma fazer na situação proposta. Esta circunstância deve ser examinada dentro de um contexto específico, pois os pensamentos ou ações do coping são sempre direcionados a condições particulares. Para avaliar e entender o processo de coping é preciso saber com que o sujeito está lidando. Quanto mais definido e focal for o contexto, mais fácil é ligar um ato ou pensamento exclusivo de coping a uma demanda situacional. Além disso, é necessário considerar o coping como um processo de constante transformação, no qual as estratégias utilizadas em determinado momento podem não ser as mesmas das avaliadas como adequadas ao enfrentamento de outra situação. Nesse sentido, implicam a avaliação, a interpretação e a representação cognitiva do fenômeno percebido e a reavaliação desse em função das mudanças ocorridas na relação com o indivíduo.

Essas estratégias foram categorizadas, inicialmente por Folkman, Lazarus, Gruen e DeLongis (1986a), em dois tipos quanto a sua função: coping focado na emoção e coping focado no problema. As estratégias de coping focado na emoção definem-se como esforços para regular o estado emocional associado ao evento estressor. Direcionados ao nível somático ou afetivo, têm por função reduzir as sensações desagradáveis de um estado de estresse para o que podem incluir, conforme Lazarus e Folkman (1984), distanciamento, autocontrole, evitação, minimização, atenção seletiva, comparação positiva e atribuição de valor positivo para eventos negativos. Já as estratégias de coping focado no problema constituem os esforços para atuar no fato que gerou o estresse, no sentido de alterá-lo, envolvendo desde a definição do problema e a geração de alternativas de solução até a avaliação de custo-benefício. A ação, neste caso, pode ser dirigida para si mesmo (reestruturação cognitiva como a mudança no nível de aspiração, redução do envolvimento do ego), ou para o ambiente (negociação verbal para resolução de um conflito interpessoal, busca de recursos e até mesmo agressividade). 
Esta categorização proposta por Folkman e Lazarus (1985) está entre as mais aceitas e consolidadas dentro das teorias de coping, porém crescem as controvérsias sobre tipos e classificação de estratégias. Outra proposta de entendimento do processo de coping e conseqüente diferenciação na classificação das estratégias utilizadas é o chamado "Modelo Multi-Axial de Coping" de Hobfoll (1998). Enquanto as outras abordagens (Lazarus \& Folkman, 1984; Rudolph, Denning \& Weiz, 1995), apesar de considerarem o coping dentro de uma relação do indivíduo com o ambiente, permanecem com a percepção individual do processo, Hobfoll (1998) apresenta um ponto de vista do indivíduo no contexto social. Os modelos desenvolvidos até o momento são apontados pelo autor como de profunda importância na construção do conceito, porém atingem apenas em parte sua gestalt. Para Hobfoll (1998), o social é de natureza interdependente do coping, já que esse é sempre realizado por indivíduos nidificados em famílias inseridas em um cenário social. $\mathrm{O}$ autor salienta que, em qualquer circunstância, as pessoas lidam como pessoas que estão inseridas em alguma forma de configuração familiar e em uma conjunção de membros de algum tipo de tribo que tem certas regras e guias que permeiam seus pensamentos e comportamentos. Nesse sentido, é necessário vincular o coping pessoal e social do indivíduo dentro do complexo ecológico ao tipo de estressor com o qual ele está lidando.

O modelo de Hobfoll (1998) explica o coping através de três eixos: (a) coping ativo versus passivo; (b) coping pró-social versus anti-social; e (c) coping direto versus indireto. Segundo ele, em toda e qualquer estratégia empregada acabam sendo identificadas essas três características. Tal denominação, apesar de sugerir uma perspectiva de polaridade, na verdade, tem sua concepção baseada em um processo que se encontra em movimento, como pode ser observado pela representação gráfica do modelo (Figura 1).

O eixo ativo-passivo denota o nível ou a extensão da atividade de coping. Representa o quanto a estratégia utilizada é ativamente orientada em responder aos problemas que confrontam o indivíduo. Esta dimensão é distinguível do que se tem chamado coping focado no problema, pois apesar deste tipo de estratégia ser potencialmente ativo, ele apresenta muitas outras implicações além do nível de atividade do coping. Estratégias que se aproximam mais do pólo ativo incluem a busca por suporte social e resolução de problemas, por exemplo.

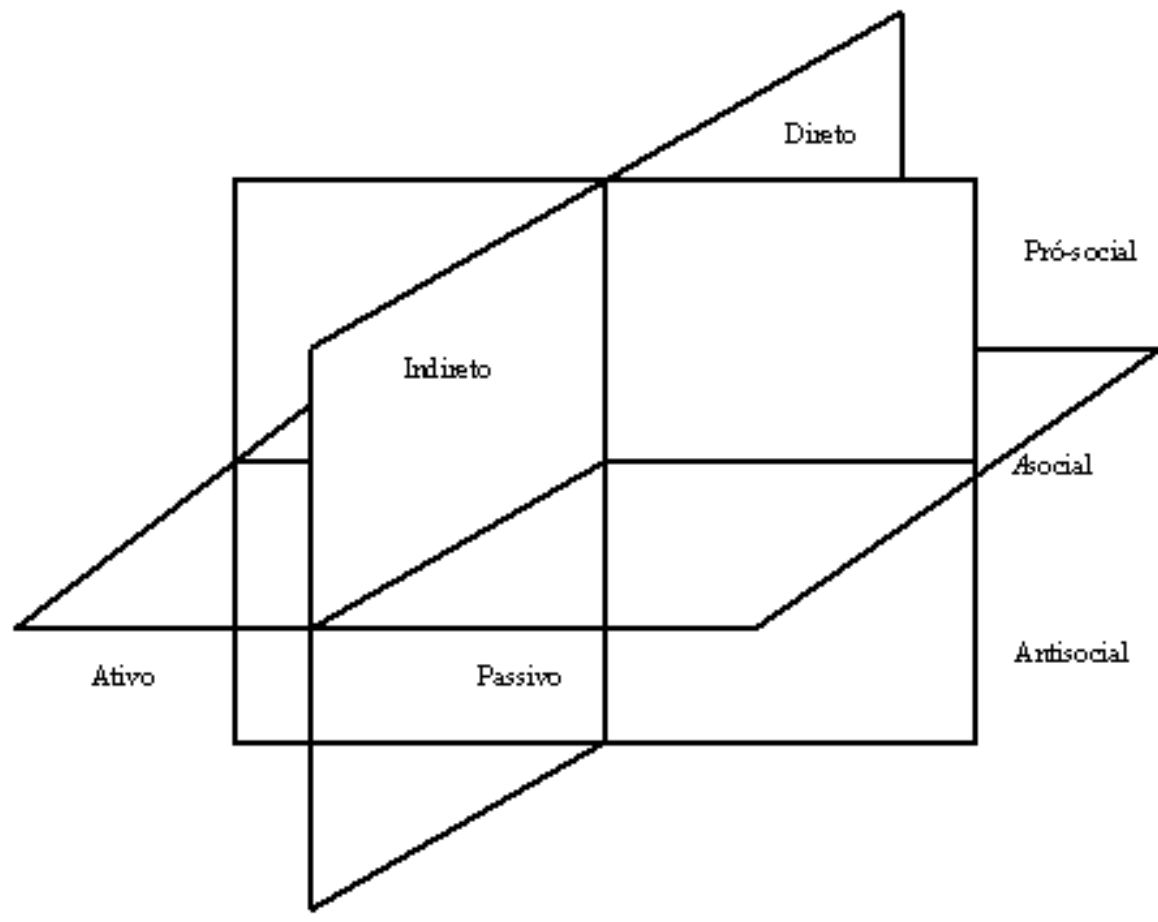


Já a evitação é considerada uma estratégia passivamente orientada (Hobfoll, 1998).

A dimensão social refere-se a como o indivíduo interage com os outros para lidar com o estressor, como define Hobfoll (1998). Este eixo compreende desde uma postura pró-social, passando pela $a$ social $^{2}$, até uma resposta anti-social. O coping pró-social envolve ações adaptativas como cuidar e/ou buscar cuidados de outros ou comportar-se positivamente nas interações sociais. As estratégias que apresentam essas características abrangem busca por suporte e tentativas de construir coalizões com outros. Estas se mostram completamente ativas, porém em algumas situações podem refletir certo nível de atividade observado pela cautela. Nestes casos, atitudes caracterizadas pelo respeito ao outro, como posturas iniciais de silêncio e evitação de contato visual, podem ser confundidas com respostas anti-sociais, mas, na verdade, denotam um comportamento pró-social cauteloso. O coping asocial encontra-se no meio desse eixo e as pessoas que atuam nesse nível, respondem imparcialmente independente do ambiente social. Um exemplo claro deste tipo de dimensão é quando um sujeito deve lidar com uma situação de exame, na qual ele estará sendo ativo no ato de estudar por si mesmo, contudo asocial acerca de sua interação com o ambiente. Por último, o coping antisocial inclui tanto a intenção de causar dano a outros como a demonstração de desprezo pelo possível dano que sua ação possa provocar. Aqui, essa dimensão é utilizada para obter vantagens sobre os outros através da exploração de suas fraquezas ou de um ataque direto como forma de alcançar uma melhor posição em termos de atingir metas e objetivos. Por outro lado, certas estratégias de coping envolvendo evitação podem ser, algumas vezes, consideradas como anti-sociais.

O eixo de direcionamento identifica se a atividade de coping é diretamente ou indiretamente aplicada ao problema. Ele diferencia-se do eixo ativopassivo, pois compreende como o coping é aplicado ao estressor levando em conta o nível da franqueza das respostas. Nesse sentido, uma estratégia de evitação do tipo abuso de substância é tida como indiretamente aplicada no enfrentamento do evento.

\footnotetext{
${ }^{2}$ Decidiu-se manter o termo usado pelo autor por não se encontrar tradução adequada.
}

$\mathrm{O}$ aspecto franqueza não determina valor positivo ou negativo à atividade de coping empregada. Um exemplo desta indiferenciação são as estratégias comumente utilizadas coletivamente. Posturas de não dizer algo que possa prejudicar a decisão do grupo, de concordar com a opinião da maioria, de não travar discussões francas como forma de esclarecer a situação ou ainda de não expressar a discordância com a posição dos outros exemplificam um coping indireto, contudo não necessariamente negativo. Geralmente, significam atos que objetivam manter a harmonia do grupo mais do que impor necessidades pessoais. A dimensão direta abarca estratégias do tipo busca ou provimento de suporte social e, até mesmo, tentativa de solução e negociação do problema.

Para avaliar este modelo foi desenvolvida por Hobfoll e sua equipe a Escala de Abordagem Estratégica do Coping (SACS). Os itens selecionados refletem ambas as estratégias de coping individual e coletivo dos mais variados tipos. O foco manteve-se em como as pessoas abordam seus problemas e utilizam seus recursos pessoais, sociais, materiais e de condições. Foram identificadas nove subescalas através do estudo de revisão de Dunahoo, Hobfoll, Monnier, Hulhizer e Johnson citado por Hobfoll (1998), a saber: (a) ação assertiva; (b) evitação; (c) busca por suporte social; (d) ação de cautela; (e) participação social; (f) ação instintiva; (g) ação agressiva; (h) ação anti-social; e (i) ação indireta. Para os autores, a escala apresenta bons indicadores de consistência interna quando comparados às propriedades psicométricas de outros instrumentos fatoriais de coping. Contudo, esses não fizeram referência aos valores da consistência interna da escala elaborada. Em outro estudo que usou o instrumento, Hobfoll e Schröder (2001) encontraram bons índices de confiabilidade das subescalas (de 0,63 a 0,83).

Assim como esses autores, outros teóricos têm-se preocupado com a construção de instrumentos para medida do coping. Tal assunto é, entretanto, gerador de discordância visto que não há homogeneidade conceitual entre as diferentes proposições teóricas e as inúmeras variáveis envolvidas no processo (Schwarzer \& Schwarzer, 1996). Sendo assim, estudos têm preconizado o entendimento do que as pessoas fazem e/ou pensam frente a situações específicas e o desenvolvimento 
de instrumentos fidedignos que capturem as particularidades de tais respostas, bem como alterações no uso de determinadas estratégias em momentos diferentes de uma mesma circunstância estressora (Seidl, Tróccoli \& Zannon, 2001).

\section{Coping e trauma}

$\mathrm{Na}$ área do trauma, as tentativas de correlacionar e compreender o processo de coping em situações traumáticas têm-se mostrado semelhantes ao contex to discuto acima. Estudos enfocando como as pessoas enfrentam eventos traumáticos são registrados desde o período da Segunda Grande Guerra, como o pertencente a Bettelheim (conforme citado por Aldwin, 1994) que investigou as mudanças das reações psicológicas em sobreviventes de campos de concentração nazistas. Tal trabalho é tido como o primeiro exemplo de pesquisa no assunto de acordo com Aldwin (1993). Nele, o autor já falava que modificações nas respostas emocionais dependem da fase da experiência traumática e de diferenças individuais em avaliar e enfrentar o evento. Além disso, comentava de que maneira o coping e os mecanismos de defesa contribuem para a sobrevivência em situações extremas, já apontando para o conteúdo dos estudos atuais sobre coping e trauma.

A literatura que focaliza estes dois conceitos tem se desenvolvido independentemente da literatura em geral sobre coping e estresse. Isto ocorre em função do trauma, diferentemente de outros estressores, envolver eventos que ameaçam a ocorrência de lesões severas incluindo perda da vida, iniciando de maneira rápida e freqüentemente atingindo um número extenso de indivíduos (Aldwin, 1994). Definição similar para um estressor traumático oferece o DSM-IV-R (American Psychiatric Association, 2003), o qual se configura em um evento real ou ameaçador que envolve morte, ferimento sério ou ameaça à integridade física do sujeito. Eventos traumáticos vivenciados diretamente podem compreender combate militar, agressão pessoal violenta (ataque sexual, roubo), seqüestro, ser tomado como refém ou encarcerado como prisioneiro de guerra, ataque terrorista, tortura, desastres naturais ou tecnológicos, graves acidentes automobilísticos ou recebimento de diagnóstico de doença que acarreta risco de vida.

Outras circunstâncias mais específicas são citadas na literatura como se referindo a trauma, entretanto, Aldwin (1994) aponta algumas vantagens em limitar o conceito a estressores extremos. A primeira diz respeito à identificação mais objetiva do estressor e das variáveis que influenciam a resposta da pessoa. Nesse sentido, características de personalidade (como o neuroticismo, por exemplo) desempenham papel importante em eventos de vida diários, mas não têm muita razão de serem consideradas em situações nas quais o indivíduo é atingido por terremotos, furacões ou guerras. Segundo, um evento traumático comumente requer uma completa mobilização de recursos com vistas à sobrevivência, promovendo, assim, um quadro relevante do uso das estratégias de coping por parte do sujeito. Por último, o trauma tem uma sensação qualitativa diferente da dos demais estressores, pois hiperrea-tividades e flashbacks, característicos do transtorno de estresse póstraumático, estão geralmente mais associados a combates e a outros traumas maiores do que a eventos estressantes do dia-a-dia.

A abordagem processual de entendimento do coping é especialmente indicada por Aldwin (1993) para o estudo das respostas ao trauma em função dessas se modificarem ao longo da experiência traumática. É com base nesta vertente, que se propõe o modelo de Hobfoll (1998) como uma alternativa no entendimento do coping de vítimas de desastres naturais. A necessidade de se considerar e analisar a relação da pessoa com o seu ambiente como parte da compreensão do processo de coping em situações de desastres naturais pede por um modelo explicativo que se caracterize por uma interpretação ecológica e social do fenômeno.

$\mathrm{Na}$ área da Psicologia, a literatura internacional interessada pelas consequiências psicológicas de vítimas envolvidas em circunstâncias traumáticas é extensa (Norris, 2002) e tem enfatizado mais as respostas subjetivas dos indivíduos em relação ao trauma do que propriamente a gravidade desse (Arnt, Spitz \& Zaidhaft, 2001). Nesse contexto, ainda se pode observar a revolução sócio-cultural-ambiental que tem afetado a relação entre as nações, a configuração da vida familiar, e ainda possivelmente os padrões conhecidos de indivíduo (Ackerman, 1986). Seres humanos e relações humanas são lançados em um estado de turbulência, no qual ocorre uma crescente redução de espaço e uma forçada intimidade de pessoas convivendo em culturas 
conflitantes. Tal realidade requer uma nova visão das relações do ser humano com o outro e com seu ambiente.

\section{Desastres naturais e coping}

No campo do trauma, segundo Aldwin (1994), os eventos podem ser divididos em três tipos: desastres naturais e tecnológicos, guerras e problemas relacionados como a fome, e trauma individual. Atualmente, entre os mais comuns tipos de trauma estão os desastres entendidos como eventos ambientais estressantes que ocorrem em larga escala e que afetam adversamente um significante número de pessoas (Briere \& Elliot, 2000). É um evento súbito que tem o poder de aterrorizar ou gerar perdas substanciais de muitos indivíduos simultaneamente (Norris, 2002). Considerados atípicos, seu impacto excede a possibilidade de uma comunidade em lidar com seus efeitos através de recursos próprios (Arcos, González, Huerta \& Cueto, 1994). Um desastre caracteriza-se, segundo a Secretaria Nacional de Defesa Civil (2008), por uma situação em que o município necessita tomar medidas excepcionais, de urgência, ou ainda, comprometer toda sua capacidade administrativa. Mais especificamente os desastres naturais são divididos pelo Ministério da Integração Nacional (2005) em função de suas causas: de origem sideral, de causa eólica e relacionados com temperaturas extremas, intensa redução das precipitações hídricas e inundações, sismologia, vulcanologia, geomorfologia, o intemperismo, a erosão, a acomodação do solo e desequilíbrios da biocenose.

De acordo com estudos internacionais, dados oficiais registraram, nas últimas décadas, um crescimento de desastres naturais no mundo. De 2000 a 2005, por exemplo, foram registrados 2.788 desastres (http://www.unisdr.org/disaster-statistics/ pdf/isdr-disaster-statistics-occurrence.pdf). Em 2007, foram aproximadamente 380 desastres (http:// www.unisdr.org/eng/media-room/facts-sheets/2007disasters-in-numbers-ISDR-CRED.pdf). Ainda sobre a prevalência, $13 \%$ a $30 \%$ dos indivíduos da população em geral já foram expostos a um ou mais desastres naturais durante sua vida, conforme Green e Solomon, citados por Briere e Elliot (2000). Os últimos, em sua própria pesquisa, encontraram dados próximos a estes, nos quais $22 \%$ dos participantes relataram já ter passado por circunstâncias como essa. Em termos de estatísticas de desastres, no Brasil não foram encontrados registros pela Defesa Civil do país.

Outro aspecto importante na área é que a maioria das investigações tem sido conduzida em países desenvolvidos, conforme destacam Cao, MacFarlane \& Klimidis (2003), salvo algumas exceções como estudos na China (Wang e cols., 2000), Índia (Sharan, Chaudhary, Kavathekar \& Saxena, 1996), Armênia (Armenian e cols., 2000) e Nicarágua (Caldera, Palma, Penayo \& Kullgren, 2001). Na sua revisão, Norris e cols. (2002) apontam que uma menor parte dos estudos foi realizada nos países em desenvolvimento (31\%) enquanto $69 \%$ foram conduzidos nos países desenvolvidos. Os autores ainda enfatizam a presença de maiores problemas metodológicos nas pesquisas realizadas nos países em desenvolvimento, principalmente no que diz respeito aos procedimentos de seleção das amostras e a delineamentos longitudinais. Somente $19 \%$ das amostras tinham alta representatividade se comparadas com $42 \%$ das amostras americanas e $47 \%$ das de outros países desenvolvidos. Quanto às estratégias longitudinais, apenas quatro estudos (11\%) foram encontrados em países em desenvolvimento, contra $27 \%$ e $38 \%$ de prevalência nos EUA e nos demais países desenvolvidos, respectivamente. Desenhos desse tipo requerem maior infra-estrutura e financiamento para sua execução, fatores que podem explicar tal contexto.

Esse escasso conhecimento sobre o impacto dos desastres naturais nos países em desenvolvimento, onde o número de mortes desta natureza e o impacto psicológico são significativamente maiores, torna imperativa a preocupação com a produção científica nesta área (Cao e cols., 2003; Norris e cols., 2002). $\mathrm{O}$ efeito mais evidente dessa carência é que tais comunidades sofrem de privações socioeconômicas sérias e possuem recursos insuficientes para enfrentar situações de calamidade (Sharan e cols., 1996). Os dados de Norris e cols. (2002) mostram que mais de $50 \%$ das amostras vítimas de desastres nos países em desenvolvimento padecem de sofrimento psicológico clinicamente grave ou de transtornos psiquiátricos.

Particularmente no Brasil, onde eventos ambientais como tornados e inundações têm sido mais comuns do que há tempos atrás, existe pouca produção científica sobre o assunto no domínio da 
Psicologia. As pesquisas realizadas nessa área iniciaram-se e mantêm sua maior concentração no campo de estudo da Psicologia Ambiental (Pinheiro, 1997), que preconiza a idéia de que qualquer questão ambiental é na verdade uma questão humanoambiental. Sendo assim, as crises ambientais, como amplamente denominadas por esses estudiosos, são crises das pessoas-nos-ambientes. Essa proposta de compreensão associa-se claramente à proposta de definição de desastre das Ciências Sociais, um evento que resulta não apenas da forma como as pessoas enfrentam o problema, mas como habitam o lugar e se relacionam entre si (indivíduos e coletividade) e com o ambiente. É um evento que impacta a sociedade, originado de um padrão específico de interação entre um fenômeno natural e uma organização social (Marandola Jr. \& Hogan, 2004; Mattedi \& Butzke, 2001).

Pinheiro (1997) discute os possíveis obstáculos que vêm contribuindo para que a Psicologia não esteja conseguindo responder a todas as perguntas que as crises ambientais têm colocado à sociedade, bem como alguns fatores responsáveis por tais crises. Além disso, a Psicologia Ambiental relacionada aos desastres desenvolve conceitos que incluem ambiente de risco, relação sujeito-ambiente, muitas vezes apresentados por modelos que apresentam a interrelação entre eles. Já investigações acerca das conseqüências e dos processos psicológicos decorrentes desses eventos parecem estar iniciando sua jornada. No Brasil, o único estudo encontrado abordando esses aspectos foi o de Coêlho, Adair e Moccelin (2004) que, ao pesquisar a seca, concluíram que se trata de um desastre que causa forte impacto populacional em vários aspectos, mesmo que de maneira gradual. A pesquisa foi conduzida em duas comunidades no estado da Paraíba, das quais foram selecionados 102 chefes de famílias de cada comunidade, sendo apenas uma atingida pela seca, a outra foi caracterizada como o grupo controle. A avaliação incluiu três instrumentos acerca do nível de ansiedade (STAI), de sofrimento emocional (SRQ20) e de incidência de estresse pós-traumático (TSQ) com o objetivo de comparar as respostas nos dois grupos. Os resultados mostraram um nível significativamente mais alto de ansiedade e sofrimento emocional nos residentes da área de seca em comparação aos que residem na área não-atingida pelo evento. Por outro lado, o transtorno de estresse pós-traumático não se relacionou com a seca, como já era esperado pelos pesquisadores, em função de sua característica em produzir efeitos graduais.

\section{Estudos recentes: uma perspectiva para o coping coletivo}

Estudos com pessoas vítimas de desastres, como assinalam Coêlho e cols. (2004), têm modificado o foco do campo de investigação sobre stress, e as respostas psicológicas, comumente relacionadas a traumas individuais. O novo foco busca entender o impacto dos desastres em comunidades inteiras ou grupos representativos, nos quais cada vez mais são realizadas pesquisas com grupos controles ou de comparação, com delineamentos prospectivos de observações por períodos mais longos e com avaliações mais adequadas através de instrumentos e entrevistas apropriados.

Em relação a estudos qualitativos acerca do coping em situações de desastres, esses não são muito freqüentes mesmo nos países desenvolvidos. Foi encontrada a investigação de Norris e cols. (2001) com uma amostra heterogênea de adultos mexicanos $(n=24)$ como forma de avaliar as construções particulares da experiência do trauma e de suas seqüelas. Parte dos participantes havia sido atingida por um desastre tecnológico (explosão de esgoto em Guadalajara em 1992) e outra porção foi vítima de dois furacões na Flórida e em Oaxaca (Andrew em 1992 e Pauline em 1997, respectivamente). A avaliação foi feita em 1997, através de entrevista nãoestruturada, mas iniciada com o que os autores consideraram a pergunta norteadora: Como o desastre afetou você e os outros que viviam aqui ? Essa tinha a função de introduzir o tema de forma ampla. Tal técnica tinha o poder de eliciar desde a descrição do evento em si, os sentimentos associados, o tipo de ajuda que a pessoa recebeu ou forneceu aos outros, até o processo de recuperação do trauma. As entrevistas foram conduzidas na casa ou local de trabalho, mas nem sempre de forma individual, como planejado previamente. Em algumas situações, os indivíduos convidavam familiares ou crianças que estavam presentes durante o encontro. Tais informações não foram descartadas da análise em função do próprio objetivo do estudo. Sendo esse relacionado a investigação qualitativa das experiências 
do trauma, um enfoque que considere a visão da cultura e não somente do indivíduo se fez interessante. Quanto aos dados, estes foram levantados pela análise de conteúdo e refletiram a importância dos efeitos seguidos ao trauma, mostrando que é possível avaliar as seqüelas a partir da narrativa dos participantes.

Estudo derivado desse e que focalizou as estratégias de coping mais empregadas pelas comunidades mexicanas para enfrentar situações de desastres foi o de Ibañez, Buck, Khatchikian e Norris (2004), que utilizaram uma amostra semelhante a do estudo anterior (27 adultos mexicanos), dividida nas mesmas três regiões (Guadalajara, Flórida e Oaxaca), sendo o procedimento aplicado similar, através de entrevistas individuais não-estruturadas com uma pergunta norteadora inicial. No entanto, foram acrescentadas perguntas descritivas divididas em questões de exemplo (Você pode me dar exemplos de como os outros ajudaram você??) e questões de experiência (Descreva sua experiência de lidar com seu dia-a-dia após o desastre?). Embora a investigação tivesse característica exploratória, algumas hipóteses como a utilização freqüente da estratégia de coping pró-social e da referência indireta a alguns estilos de coping eram esperadas. A análise de conteúdo realizada não observou diferenças culturais no emprego das estratégias de coping entre sobreviventes mexicanos. Quatro foram os temas recorrentes, que deram origem às categorias analíticas. A mais freqüente das categorias mencionadas nas amostras das três localidades, denominada busca por suporte, envolvia busca ativa de suporte através da expressão das emoções para outras pessoas ou do próprio provimento de suporte. Tal categoria foi relacionada pelos autores ao tipo de estratégia de coping focada socialmente e classificada, conforme modelo de Hobfoll (1998), como tendo característica ativa, pró-social e direta. Os autores ainda sugeriram que essa estratégia seja encarada como universal no comportamento de vítimas de desastres naturais. Outra categoria temática interpretada como contendo as mesmas dimensões, porém focada no problema, foi definida como resolução de problemas, incluindo os esforços ativos na solução e/ou negociação de um problema. A terceira categoria encontrada, a evitação, abarca esforços de recusa em lidar com o problema por meio de distração pessoal, racionalização, distanciamento e até mesmo abuso de substâncias. As estratégias de coping envolvidas nesse agrupamento foram caracterizadas como passivas, anti-sociais e indiretas e são indicadas como focadas na emoção.

A última categoria diz respeito à busca por significado, a qual articula esforços para dar sentido ao evento através da espiritualidade ou da tentativa de aprender com o trauma. Para os pesquisadores, este tipo de estratégia não é contemplado na teoria de Hobfoll, mas emergiu dos próprios dados coletados. Essa investigação atenta para os tipos de estratégias de coping possíveis de serem encontradas entre vítimas de desastres; as socialmente focadas mostraram-se as mais comuns, segundo os autores, provavelmente porque a interação com outras pessoas em situações desta natureza é inevitável. As diferenças encontradas entre as amostras das cidades no que diz respeito às categorias de resolução de problemas e de evitação sugerem que as estratégias de coping utilizadas por sobreviventes de desastres podem variar conforme fatores do contexto como: tipo de desastre, extensão dos danos e das mortes, recursos disponíveis e estágio de recuperação da comunidade.

\section{Considerações finais}

Considerando estas variações e a escassez de estudos explorando especificamente a associação entre coping e desastres naturais, torna-se imperativo o desenvolvimento de um olhar mais apurado para este contexto. É necessário atentar para todos os aspectos acerca dos conceitos de estresse e coping, bem como seus respectivos modelos teóricos discutidos ao longo desse trabalho e aliá-los à conjuntura global atual que tem refletido uma crise que traz consigo o aumento da sensação de medo e da vivência de experiências traumáticas. Sentimentos de desconfiança e ameaça constantes provenientes da violência urbana (Arnt e cols., 2001), situações de tensão entre povos que provocam guerras infindáveis (Norris e cols., 2002) e a própria inconstância ambiental resultando nos mais diversos episódios de desastres naturais nos últimos anos (Briere \& Elliot, 2000; Norris e cols., 2002) são parte corriqueira da paisagem atual do planeta.

Dentro desta perspectiva, Ackerman (1986) atenta para o fato de que em qualquer ponto do tempo e do espaço, o indivíduo é o receptor de uma 
experiência grupal. Sua identidade, desenvolvimento e reação são simultaneamente individuais e sociais. A partir disso, e tomando a afirmação de Foley (1990) de que um evento é sempre resultado de uma interação dentro de um sistema e por isso não pode ser entendido isoladamente, Ackerman (1986) aponta que a análise de um evento traumático deve englobar o indivíduo dentro do grupo bem como o próprio grupo. O trauma que afeta o indivíduo, a família e a sociedade devem ser considerados em um continuum. Nesse sentido, o desastre natural deve, da mesma forma, ser entendido como uma violação do equilíbrio do sistema como um todo, não podendo uma compreensão integrada desta experiência prescindir de um olhar social de como suas vítimas enfrentam tal fenômeno.

\section{Referências}

Ackerman, N. W. (1986). Diagnóstico e tratamento das relações familiares. Porto Alegre: Artes Médicas.

Aldwin, C. M. (1993). Coping with traumatic events. PTSD Research Quarterly, 4(3), 1-8.

Aldwin, C. M. (1994). Stress, coping and development: An integrative perspective. New York: The Guilford Press.

American Psychiatric Association (APA). (2003). DSM-IV: Diagnostic and statistical manual of mental disorders (4th ed.). Washington, DC: Author.

Arcos, P. G., González, F. C., Huerta, M. G., \& Cueto, A. E. (1994). The concept of disaster and its application in Asturias. Revista de Sanidad e Higiene Publica, 68, 573-578.

Armenian, H. K., Morikawa, M., Melkonian, A. K., Hovanesian, A. P., Haroutunian, N., Saigh, P. A., Akiskal, K., \& Akiskal, H. S. (2000). Loss as a determinant of PTSD in a cohort of adult survivors of the 1988 earthquake in Armenia: Implications for policy. Acta Psychiatrica Scandinavica, 102, 58-64.

Arnt, R. A., Spitz, L., \& Zaidhaft, S. (2001). Trauma: Aspectos psicológicos e psiquiátricos. In E. Freire (Ed.), Trauma: A doença dos séculos (pp. 493498). São Paulo: Atheneu.
Briere, J., \& Elliott, D. (2000). Prevalence, characteristics, and long-term sequelae of natural disaster exposure in the general population. Journal of Traumatic Stress, 13, 661-678.

Bronfenbrenner, U. (1996). A ecologia do desenvolvimento humano: Experimentos naturais e planejados. Porto Alegre: Artes Médicas.

Caldera, T., Palma, L., Penayo, U., \& Kullgren, G. (2001). Psychological impact of the Hurrican Mitch in Nicaragua in a one-year perspective. Social Psychiatry and Psychiatric Epidemiology, 36, 108-114.

Cao, H., MacFarlane, A. C., \& Klimidis, S. (2003). Prevalence of psychiatric disorder following the 1988 Yun Nan (China) earthquake: The first 5month period. Social Psychiatry and Psychiatric Epidemiology, 38, 204-212.

Coêlho, A. E. L., Adair, J. G., \& Mocellin, J. S. P. (2004). Psychological responses to drought in northeastern Brazil. Interamerican Journal of Psychology, 38, 95-103.

Foley, V. D. (1990). Introdução à terapia familiar. Porto Alegre: Artes Médicas.

Folkman, S., \& Lazarus, R. S. (1985). If it changes it must be a process: Study of emotion and coping during three stages of a college examination. Journal of Personality and Social Psychology, 48, 150-170.

Folkman, S., Lazarus, R. S., Gruen, R. \& DeLongis, A. (1986a). Appraisal, coping, health status, and psychological symptoms. Journal of Personality and Social Psychology, 50, 571-579.

Hobfoll, S. E. (1989). Conservation of resources: A new attempt at conceptualizing stress. American Psychologist, 44, 513-524.

Hobfoll, S. E. (1998). Stress, culture, and community: The psychology and philosophy of stress. New York: Plenum Press.

Ibañez, G. E., Buck, C. A., Khatchikian, N., \& Norris, F. H. (2004). Qualitative analysis of coping strategies among Mexican disaster survivors. Anxiety, Stress, and Coping, 17, 69-85. 
Lazarus, R. S., \& Folkman, S. (1984). Stress, appraisal, and coping. New York: Springer.

Marandola Jr., E., \& Hogan, D. J (2004). Natural hazards: O estudo geográfico dos riscos e perigos. Ambiente e Sociedade, 7, 95-110.

Mattedi, M. A., \& Butzke, I. C. (2001). A relação entre o social e o natural nas abordagens de hazards e de desastres. Ambiente e Sociedade, 9, 93-114.

Ministério da Integração Nacional (2005). Manual de desastres: Desastres naturais. Brasília: Autor.

Norris, F. H., Weisshaar, D. L., Conrad, M. L. I., Diaz, E. M., Murphy, A. D., \& Ibañez, G. E. (2001). A qualitative analysis of posttraumatic stress among Mexican victims of disaster. Journal of Traumatic Stress, 14, 741-756.

Norris, F. H. (2002). Psychosocial consequences of disasters. PTSD Research Quarterly, 13(2), 18.

Norris, F. H., Friedman, M. J., Watson, P. J., Byrne, C. M., Diaz, E., \& Kaniasty, K. (2002). 60,000 disaster victims speak: Part I. An empirical review of the empirical literature, 1981-2001. Psychiatry, 65, 207-239.

Pinheiro, J. Q. (1997). Psicologia Ambiental: A busca de um ambiente melhor. Estudos de Psicologia, 2, 337-398.

Rudolph, K. D., Denning, M. D., \& Weisz, J. R. (1995). Determinants and consequences of children's coping in the medical setting: Conceptualization, review, and critique. Psychological Bulletin, 118, 328-357.

Secretaria Nacional de Defesa Civil (2008). Situação de emergência e estado de calamidade pública. Retirado em 29 fevereiro 2008, de http:// www.defesacivil.gov.br/situacao/index.asp.

Schwarzer, R., \& Schwarzer, C. (1996). A critical survey of coping instruments. In M. Zeidner \& N. S. Endler (Eds.), Handbook of coping: Theory, research, applications (pp. 107-132). New York: Wiley.
Seidl, E. M. F., Tróccoli, B. T., \& Zannon, C. M. L. C. (2001). Análise fatorial de uma medida de estratégias de enfretamento. Psicologia: Teoria e Pesquisa, 17, 225-234.

Sharan, P., Chaudhary, G., Kavathekar, S. A., \& Saxena, S. (1996). Preliminary report of psychiatric disorders in survivors of a severe earthquake. American Journal of Psychiatry, 153, 556-558.

Suls, J., David, J. P., \& Harvey, J. H. (1996). Personality and coping: Three generations of research. Journal of Personality, 64, 711-735.

Wang, X., Gao, L., Shinfuku, N., Zhang, H., Zhao, C., \& Shen, Y. (2000). Longitudinal study of earthquake-related PTSD in a randomly selected community sample in north China. American Journal of Psychiatry, 157, 1260-1266.

Artigo recebido em 21/07/2007.

Aceito para publicação em 29/03/2008.

Derivado de dissertação de mestrado da primeira autora sob orientação da segunda autora, com apoio financeiro do $\mathrm{CNPq}$.

Endereço para correspondência:

Profa. Dra. Denise Ruschel Bandeira. Universidade Federal do Rio Grande do Sul. Instituto de Psicologia. Rua Ramiro Barcelos, 2600 sala 120, Santa Cecília. CEP: 90035-003. Porto Alegre-RS, Brasil.E-mail: drbandei@terra.com.br

Fernanda Menna Barreto Krum é mestre em Psicologia pela Universidade Federal do Rio Grande do Sul.

Denise Ruschel Bandeira é Professor Adjunto do Instituto de Psicologia da Universidade Federal do Rio Grande do Sul. 